\title{
Substituição de areia de quartzo por finos de gnaisse em massa cerâmica para telhas: Teste industrial
}

\author{
(Replacing quartz sand for gnaisse fines waste into \\ roofing tile body: Industrial test)
}

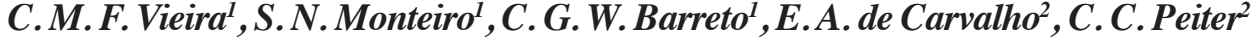 \\ ${ }^{1}$ Laboratório de Materiais Avançados - LAMAV, Universidade Estadual do Norte Fluminense Darcy Ribeiro - UENF \\ Av. Alberto Lamego 2000, Campos dos Goytacazes, RJ 28015-620 \\ ${ }^{2}$ Centro de Tecnologia Mineral - CETEM, Av. Ipê 900, Ilha da Cidade Universitária, Rio de Janeiro, RJ \\ vieira@uenf.br
}

\begin{abstract}
Resumo
Foi avaliado o efeito da substituição de areia por um resíduo de beneficiamento de rocha ornamental, finos de gnaisse, em uma massa de cerâmica vermelha utilizada para fabricação de telhas. Foram preparadas telhas prensadas, do tipo "portuguesa", para queima a $900{ }^{\circ} \mathrm{C}$ em forno industrial. As seguintes propriedades foram determinadas: retração linear, absorção de água e carga de ruptura na flexão. Além disso, avaliaram-se as características das matérias-primas e a plasticidade das composições por meio dos limites de Atterberg. Os resultados indicaram que a utilização de finos de gnaisse em substituição à areia possibilitou uma melhoria na trabalhabilidade/plasticidade da massa cerâmica e acarretou uma pequena redução na absorção de água das telhas. A resistência mecânica não se alterou, dentro da precisão estatística das medidas.
\end{abstract}

Palavras-chave: areia, cerâmica vermelha, reformulação, gnaisse, resíduo.

\begin{abstract}
The effect of replacing sand for gnaisse sawing waste into a red ceramic body used for roofing tile fabrication was evaluated. Pressed roofing tiles, "portuguese" style, were prepared before firing at $900{ }^{\circ} \mathrm{C}$ in an industrial furnace. The following properties were evaluated: linear shrinkage, water absorption and load rupture strength. The plasticity of the elaborated compositions was determined by the Atterberg limits. The results show that the use of gnaisse fines replacing the sand, improved the workability of the ceramic body and promoted a slight decrease on the water absorption of the roofing tiles. The mechanical strength was not changed within the statistical error.
\end{abstract}

Keywords: sand, red ceramic, reformulation, gnaisse, waste.

\section{INTRODUÇ̃̃O}

O Segmento de Rochas Ornamentais em Santo Antônio de Pádua, situado ao noroeste do Estado do Rio de Janeiro, constitui a principal atividade econômica do município com geração de 6.000 empregos e faturamento de 4 milhões de dólares/mês [1]. As pedras extraídas do município e utilizadas como rochas ornamentais são denominadas comercialmente de granitos e, após beneficiamento, são utilizadas como revestimento de paredes, muros, pisos, etc. [2]. A rocha existente na região é um granulito milotinizado com variedades locais conhecidas como "pedra olho de pombo", "granito fino", "granito pinta rosa" e "pedra madeira" [3]. Após a atividade de lavra, os blocos e lajes brutas preparadas nas pedreiras, são enviados para as serrarias para a obtenção do produto final. O corte de blocos de granitos nas serrarias gera uma quantidade apreciável de rejeito na forma de polpa abrasiva chamado de "lama", denominada neste trabalho de finos de gnaisse. Esta lama é descartada diretamente em córregos e rios da região ou enviada para tanques ou lagoas de decantação. Estes locais de despejo assim que ficam saturados, necessitam do descarte do resíduo com grandes transtornos ambientais e custo elevado. Estima-se que as cerca de 40 serrarias de Santo Antônio de Pádua gerem aproximadamente 1.200 toneladas de lama/mês, o que vem acarretando sérios problemas ambientais na região.

A partir das lajes provenientes das pedreiras, ocorre um corte com disco diamantado para redução do tamanho das lajes para $20 \mathrm{~cm} \times 30 \mathrm{~cm}$, gerando os blocos. Nesta etapa utiliza-se água para a refrigeração do processo de corte, acarretando a geração da lama que é despejada em tanque de decantação. Posteriormente, a lama é bombeada para um outro tanque visando seu armazenamento. Uma alternativa tecnológica para a reciclagem deste tipo de resíduo é a incorporação em cerâmica vermelha. $\mathrm{O}$ setor cerâmico utiliza a argila como matéria-prima principal para a obtenção 
de seus produtos como blocos de vedação (tijolos comuns), tijolos aparentes, blocos estruturais, telhas, pisos rústicos e manilhas. A argila é constituída pelos argilominerais, apresentando como impurezas mais comuns o quartzo e os hidróxidos de alumínio e ferro, além de mineral micáceo e matéria orgânica $[4,5]$.

O município de Campos dos Goytacazes, localizado no norte do Estado do Rio de Janeiro, e cerca de $150 \mathrm{~km}$ do município de Santo Antônio de Pádua, apresenta, devido as suas características geológicas, uma grande reserva de argilas $[6,7]$ o que motivou o desenvolvimento de um pólo de cerâmica vermelha há cerca de 40 anos. Atualmente, em torno de 110 indústrias extraem diariamente cerca de $8 \mathrm{mil}$ toneladas de argilas para produzir 4 milhões de peças/dia. Mais de 5000 empregos diretos estão associados às indústrias cerâmicas locais.

As empresas de cerâmica vermelha de Campos dos Goytacazes utilizam argilas locais que são altamente plásticas e de granulometria fina. Além disso, estas argilas são predominantemente cauliníticas, com elevada perda ao fogo e baixo percentual de óxidos fundentes [8-10]. Estas características conferem às argilas da região um comportamento refratário durante a queima o que dificulta a diminuição da porosidade ao nível desejado. Com isso, grande parte dos produtos apresenta porosidade excessiva o que acarreta elevados valores de absorção de água.

Uma alternativa tecnológica para reduzir a refratariedade das massas de cerâmica vermelha de Campos dos Goytacazes $\mathrm{e}$, conseqüentemente, diminuir a porosidade e melhorar a qualidade do produto final, seria incorporar matériasprimas denominadas de fundentes. Os fundentes são ricos em óxidos alcalinos e alcalino-terrosos, os quais formam eutéticos com a sílica em temperaturas típicas de queima de cerâmica vermelha $700-1000{ }^{\circ} \mathrm{C}[11,12]$.

Estudos recentes [13-16] mostraram que resíduos de granito provenientes da serragem dos blocos apresentam um grande potencial de utilização em cerâmica vermelha devido às suas características de elevada fonte de $\mathrm{K}_{2} \mathrm{O}$ e $\mathrm{Na}_{2} \mathrm{O}$ bem como granulometria fina e baixo custo. Por outro lado, os resultados das propriedades físicas e mecânicas das peças queimadas variam bastante. Vários fatores contribuem para esta variação como as características das diferentes massas argilosas e resíduos estudados, bem como a variação dos parâmetros de processamento. Portanto, não é prudente generalizar o efeito deste tipo de material em cerâmica vermelha e sim, avaliar cada caso.

Neste sentido, o presente trabalho tem como objetivo reformular uma típica massa de telhas, utilizada em Campos dos Goytacazes, por meio da substituição de areia de quartzo pelo resíduo do corte de rocha ornamental, finos de gnaisse. É também parte deste objetivo caracterizar as matériasprimas e avaliar, por meio de teste piloto, as propriedades físicas e mecânicas das telhas produzidas industrialmente.

\section{MATERIAIS E MÉTODOS}

Foram utilizadas duas argilas plásticas, areia e finos de gnaisse. As argilas plásticas são denominadas argila amarela e argila preta que, juntamente com a areia, são constituintes da massa cerâmica utilizada para fabricação de telhas por uma indústria do município de Campos dos Goytacazes, RJ. Já os finos de gnaisse foram obtidos na forma de lama dos tanques de decantação utilizados para tratamento do efluente gerado no momento do corte das lajes de uma variedade da Pedra Miracema, conhecida como "olho de pombo", proveniente de uma serraria localizada no município de Santo Antônio de Pádua, noroeste do Estado do Rio de Janeiro.

A caracterização mineralógica das matérias-primas foi realizada por meio de difração de raios X (DRX). As análises de DRX foram feitas no difratômetro Bruker-AXS D5005 com radiação $\operatorname{Cok}_{\alpha}(\lambda=1,78897 \AA)$ para $2 \theta$ de $5^{\circ}$ a $80^{\circ}$ com passo $0,02^{\circ} / 1 \mathrm{~s}$.

A caracterização química consistiu na determinação da composição química por fluorescência de raios X (FRX) em equipamento Philips PW 2400. A caracterização física consistiu na determinação da distribuição de tamanho das partículas e da massa específica real de acordo com a norma da ABNT [17].

A caracterização morfológica do resíduo foi realizada por microscopia ótica e eletrônica de varredura em um microscópio Jeol JSM 6460 LV com sistema de energia dispersiva em espectroscopia de raios X (EDS).

A Tabela I apresenta as composições investigadas. A massa MI corresponde à massa industrial padrão utilizada pela cerâmica para fabricação de telhas dos tipos romana e portuguesa. As massas MA e MB correspondem às massas reformuladas, com a substituição da areia pelo resíduo nas quantidades de 10 e $20 \%$ em peso.

A plasticidade das massas cerâmicas foi determinada de acordo com as normas ABNT NBR-7180 [18] e NBR-6459 [19], por meio da medida dos índices de Atterberg: Limite de plasticidade (LP), limite de liquidez (LL) e índice de plasticidade (IP).

Tabela I - Massas cerâmicas estudadas (\% em peso). [Table I - Studied ceramic bodies (wt.\%).]

\begin{tabular}{cccc}
\hline & \multicolumn{3}{c}{ Massas cerâmicas } \\
\cline { 2 - 4 } Matérias-primas & MI & MA & MB \\
\hline Argila Amarela & 70 & 70 & 65 \\
Argila Preta & 20 & 20 & 15 \\
Areia & 10 & - & - \\
Finos de Gnaisse & - & 10 & 20 \\
\hline
\end{tabular}

O teste piloto seguiu o processo de fabricação padrão da cerâmica para a obtenção de telhas. Inicialmente as massas foram dosadas volumetricamente com pá carregadeira, seguindo-se despejo das composições em caixão alimentador, destorroamento, homogeneização, laminação, extrusão, prensagem, secagem e queima em forno "paulistinha" com temperatura de patamar de $900{ }^{\circ} \mathrm{C}$.

As telhas foram submetidas a ensaios físicos e mecânicos para determinação da retração linear, absorção de água e 
carga de ruptura de acordo com norma técnica da ABNT [20].

\section{RESULTADOS E DISCUSSÃO}

\section{Características das matérias-primas}

A Fig. 1 apresenta os difratogramas de raios $\mathrm{X}$ das matérias-primas. As argilas apresentam picos característicos da caulinita, mica, quartzo e gibsita, de acordo com a composição mineralógica das argilas de Campos dos Goytacazes [8, 9]. A areia é predominantemente constituída de quartzo. Entretanto, são observados picos de baixa intensidade da microclina e da albita. O difratograma do resíduo, finos de gnaisse, apresenta picos característicos
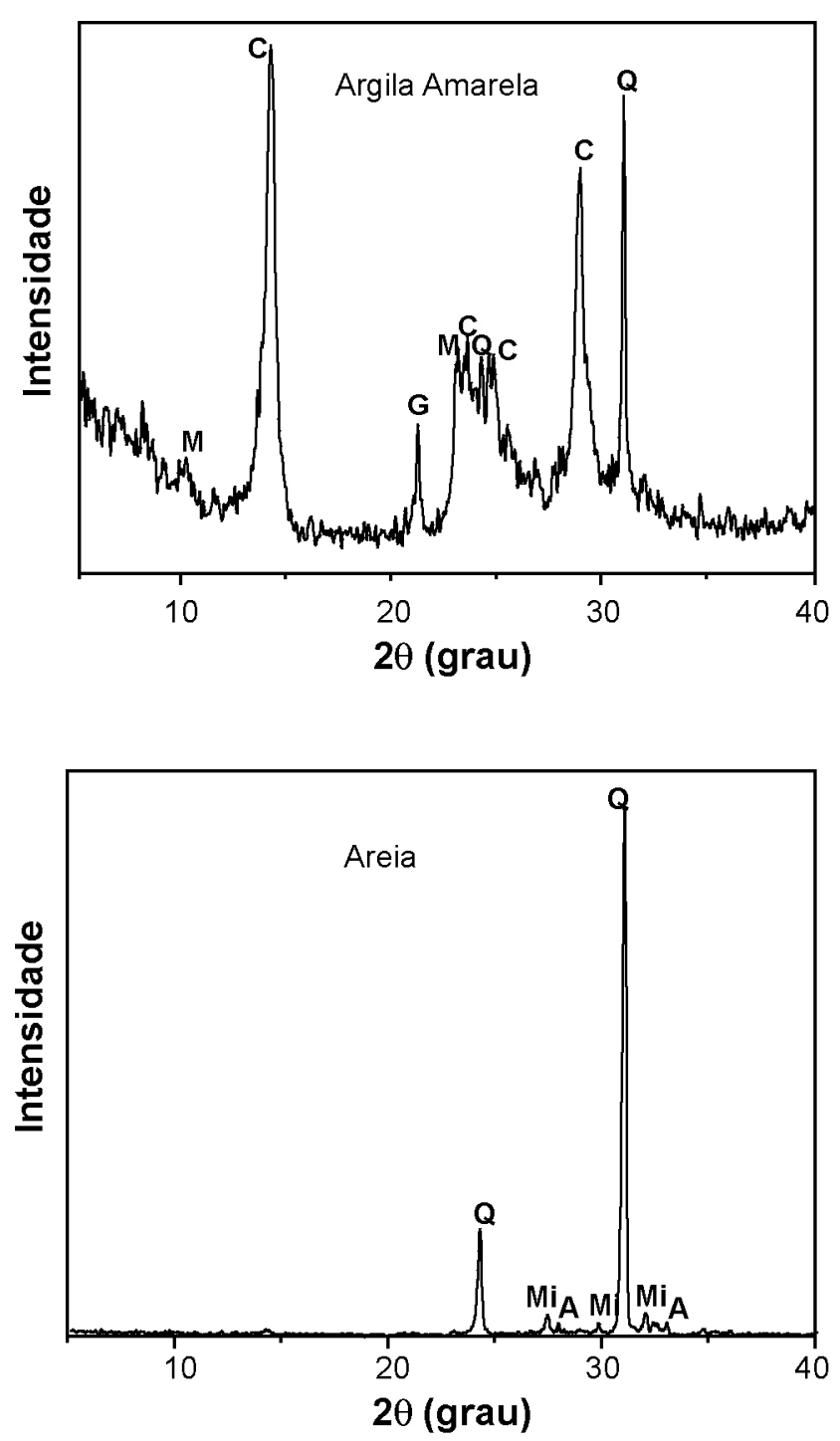

de biotita, quartzo, e de feldspatos (microclina, anortita e albita). Esta composição mineralógica classifica o resíduo como material desplastificante, o que pode ser interessante para incorporação em massas argilosas de elevada plasticidade, como as utilizadas pelas cerâmicas de Campos dos Goytacazes.

A Tabela II apresenta a composição química das matériasprimas. A argila amarela apresenta uma quantidade de $\mathrm{SiO}_{2}$ em torno de $40 \%$ e uma quantidade de $\mathrm{Al}_{2} \mathrm{O}_{3}$ acima de $30 \%$, baixos percentuais de fundentes alcalinos e alcalinoterrosos e elevada perda ao fogo (PF). Estas características são típicas de argilas cauliníticas com elevado percentual de mineral argiloso. A argila amarela ainda apresenta elevado percentual de $\mathrm{Fe}_{2} \mathrm{O}_{3}$, responsável pela coloração avermelhada da cerâmica após a queima. A argila preta apresenta um
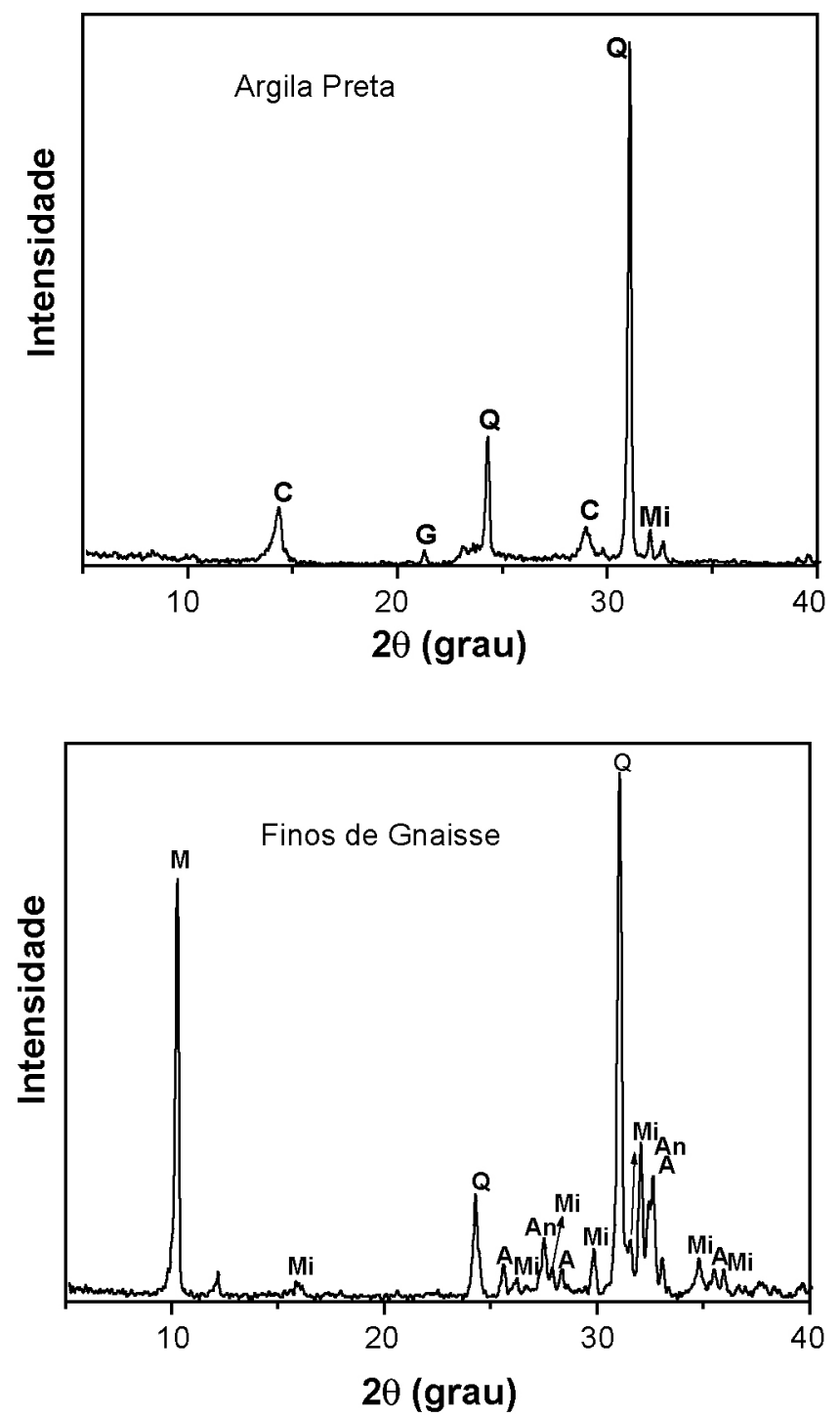

Figura 1: Difratogramas de raios X das matérias-primas. A: Albita, An: anortita, C: caulinita, G: gibsita, M: mineral micáceo, Mi: microclina, Q: quartzo.

[Figure 1: X-ray diffraction patterns of the raw materials. A: Albite, An: anorthite, $\boldsymbol{C}:$ kaolinite, $\boldsymbol{G}$ : gibssite, M: micaceous mineral, Mi: microcline, $Q$ : quartz.] 
Tabela II - Composição química das matérias-primas (\% em peso).

[Table II - Chemical composition of the raw materials (wt.\%).]

\begin{tabular}{ccccc}
\hline & $\begin{array}{c}\text { Argila } \\
\text { Amarela }\end{array}$ & $\begin{array}{c}\text { Argila } \\
\text { Preta }\end{array}$ & Areia & $\begin{array}{c}\text { Finos de } \\
\text { Gnaisse }\end{array}$ \\
\hline $\mathrm{SiO}_{2}$ & 41,22 & 69,76 & 86,66 & 67,83 \\
$\mathrm{Al}_{2} \mathrm{O}_{3}$ & 31,37 & 18,22 & 7,53 & 14,76 \\
$\mathrm{Fe}_{2} \mathrm{O}_{3}$ & 7,61 & 1,74 & 0,82 & 4,18 \\
$\mathrm{TiO}_{2}$ & 1,16 & 0,71 & 0,31 & 0,71 \\
$\mathrm{ZrO}_{2}$ & - & 0,05 & 0,04 & 0,09 \\
$\mathrm{MnO}_{2}$ & - & - & - & 0,09 \\
$\mathrm{~K}_{2} \mathrm{O}$ & 1,05 & 1,37 & 1,90 & 5,47 \\
$\mathrm{Na}_{2} \mathrm{O}$ & - & - & 0,67 & 2,77 \\
$\mathrm{CaO}$ & 0,15 & 0,28 & 0,45 & 2,08 \\
$\mathrm{MgO}$ & 0,80 & - & - & 0,73 \\
$\mathrm{P}_{2} \mathrm{O}_{5}$ & 0,21 & - & - & 0,30 \\
$\mathrm{PF}$ & 15,92 & 7,66 & 1,34 & 0,66 \\
\hline
\end{tabular}

maior teor de $\mathrm{SiO}_{2}$, menor teor de $\mathrm{Al}_{2} \mathrm{O}_{3}$ e menor $\mathrm{PF}$ em comparação com a argila amarela. Isto indica que a argila preta apresenta maior quantidade de quartzo. A areia é predominantemente constituída de $\mathrm{SiO}_{2}$ Os demais óxidos observados na composição química da areia são provenientes de impurezas como feldspato potássico, microclina, feldspato plagioclásio, a albita, conforme identificados na Fig. 1. Os finos de gnaisse apresentam elevado percentual de óxidos alcalinos $\left(\mathrm{K}_{2} \mathrm{O}+\mathrm{Na}_{2} \mathrm{O}\right)$ que são provenientes do feldspato potássico, microclina, feldspato plagioclásio, a albita, e da mica muscovita. O teor de $\mathrm{SiO}_{2}$ também está associado ao quartzo, entretanto, em menor quantidade em comparação com a areia. Já

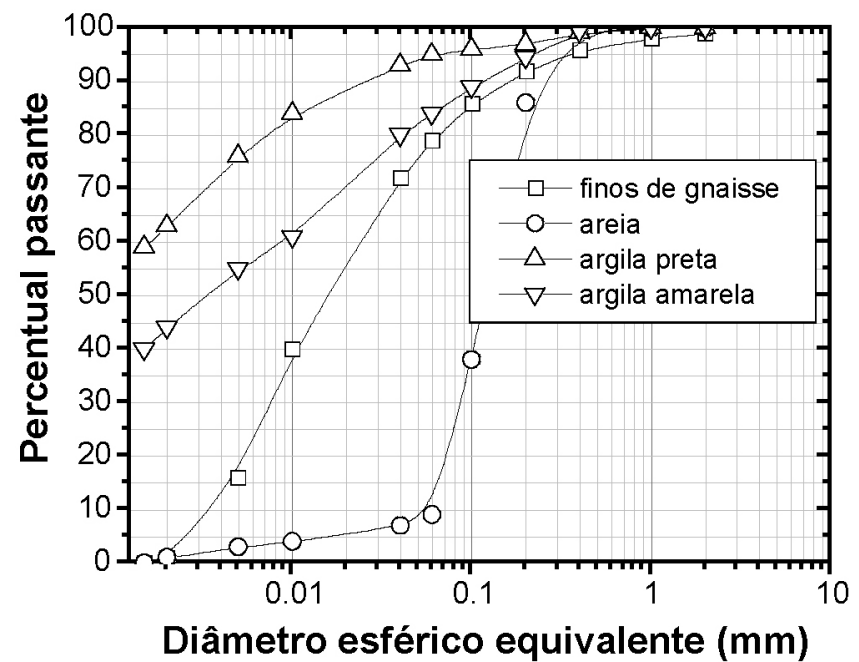

Figura 2: Curvas de distribuição de tamanho de partículas das matérias-primas.

[Figure 2: Particle size distribution curves of the raw materials.] seu teor de $\mathrm{Fe}_{2} \mathrm{O}_{3}$ de $4,18 \%$, indica uma aplicação para obtenção de produtos com cores avermelhadas.

A Fig. 2 mostra a distribuição de tamanho de partículas das matérias-primas. As argilas apresentam uma elevada quantidade de minerais argilosos, considerados por definição com tamanho de partícula inferior a $2 \mu \mathrm{m}$. Com relação aos materiais não plásticos, areia e gnaisse fino, é possível observar que o resíduo apresenta uma granulometria mais fina que a areia. A areia apresenta uma distribuição granulométrica concentrada na faixa de 0,05 a $0,5 \mathrm{~mm}$. Por outro lado, o resíduo apresenta cerca de $76 \%$ das partículas com tamanho inferior a $50 \mu \mathrm{m}$. Esta característica do resíduo é benéfica para a cerâmica já que pode possibilitar uma textura mais fina das telhas e
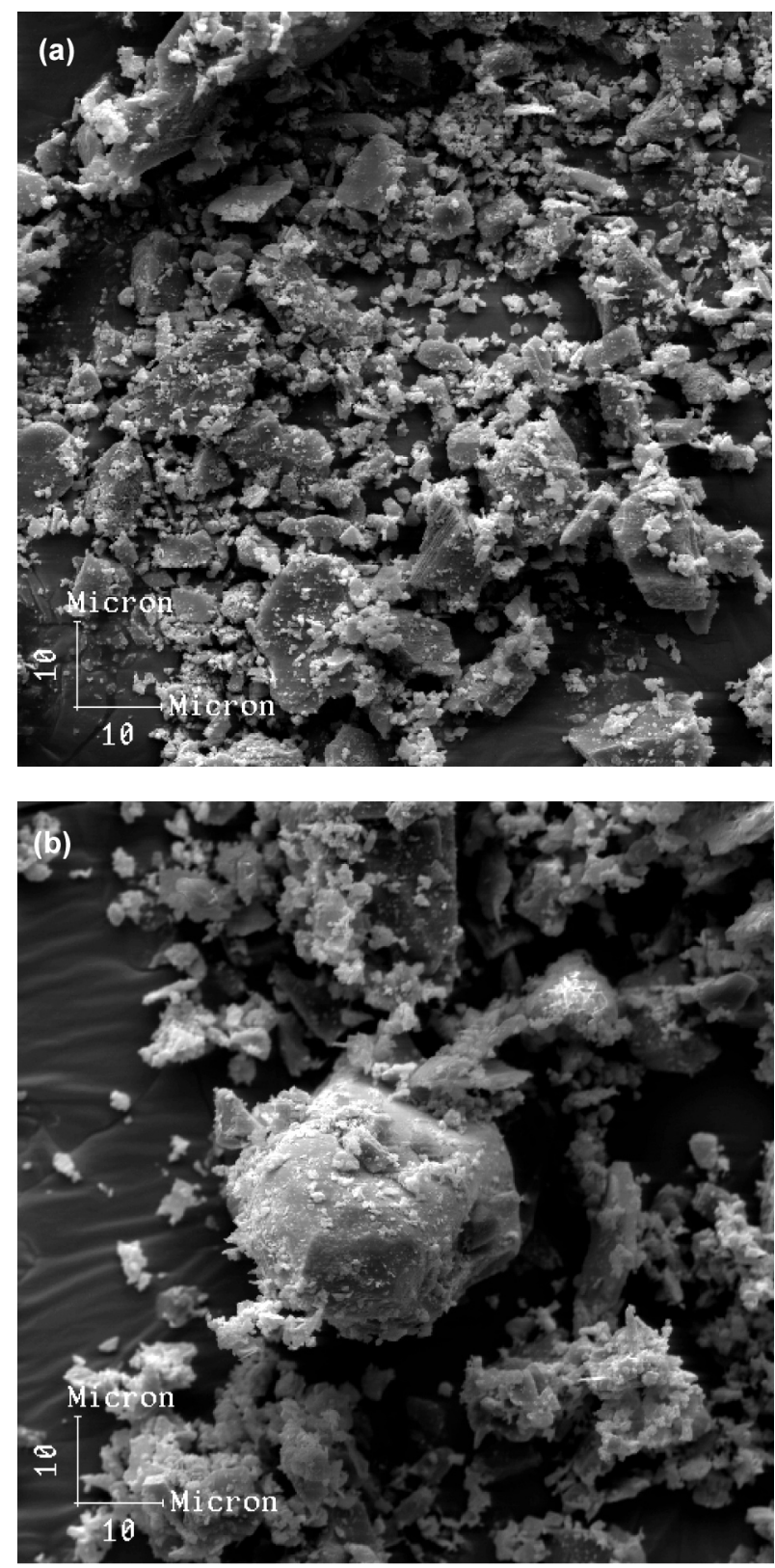

Figura 3: (a) e (b) Micrografias obtidas por MEV do gnaisse fino. [Figure 3: (a) e (b) SEM micrographs of the gnaisse fines.] 
redução de defeitos como trincas, associadas sobretudo, às partículas de quartzo de elevado tamanho.

A Fig. 3 mostra as micrografias do resíduo obtidas por MEV. O tamanho de partículas varia de submicrometro a $20 \mu \mathrm{m}$. Este dado pode ser confirmado através da curva de distribuição de partículas mostrada na Fig. 2. A Fig. 3 evidencia o tamanho submicrométrico das partículas e a formação de aglomerados. Nestas figuras é possível notar a presença de partículas que se destacam pelo tamanho e pela morfologia compacta e que, provavelmente, estão relacionadas aos grãos de quartzo presentes no resíduo.

\section{Plasticidade das formulações}

A Fig. 4 apresenta a localização das massas cerâmicas num gráfico elaborado a partir dos limites de plasticidade de Atterberg que indica regiões de extrusão ótima e aceitável [21]. O limite de plasticidade LP está associado à quantidade de água mínima necessária para que o estado de consistência plástico seja alcançado. O limite de liquidez $\mathbf{L} \mathbf{L}$ está associado à quantidade de água em que o material apresenta uma consistência de lama, ultrapassando, portanto, a faixa de consistência plástica. Já o índice de plasticidade IP é a diferença entre $\mathbf{L L}$ e $\mathbf{L P}$, indicando a faixa de consistência plástica. É possível observar na Fig. 4 que a massa cerâmica industrial MI localiza-se em região de extrusão aceitável. A utilização de $10 \%$ de finos de gnaisse em substituição à areia praticamente não alterou a trabalhabilidade da massa, pois ocorreu uma redução do LP e incremento do IP. Já a incorporação de $20 \%$ finos de gnaisse melhorou a trabalhabilidade da massa, posicionando-a mais próxima da região de extrusão ótima. O gráfico indica ainda que a massa avaliada pode suportar uma quantidade ainda maior de resíduo, o que possivelmente vai contribuir para melhorar ainda mais sua plasticidade/trabalhabilidade.

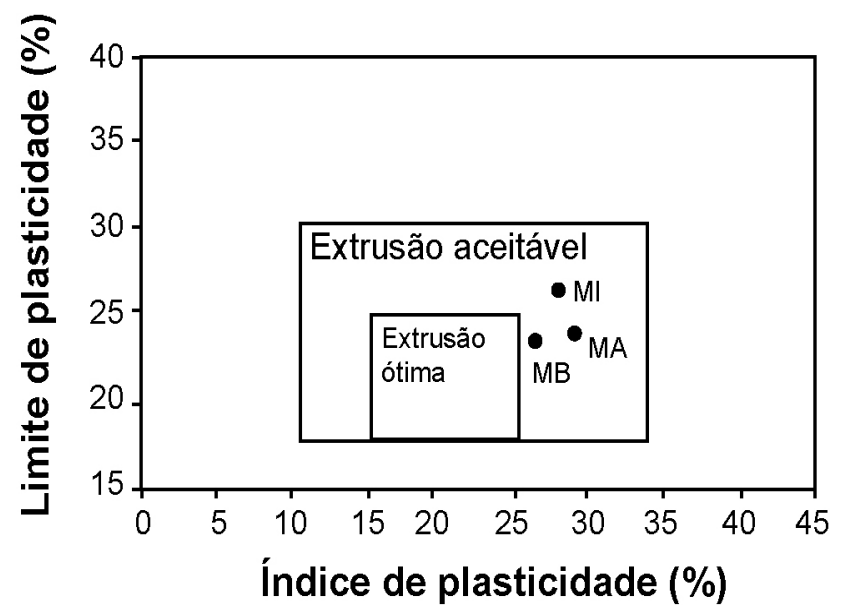

Figura 4: Prognóstico de extrusão através dos limites de Atterberg das massas cerâmicas.

[Figure 4: Extrusion prognosis throught the Atterberg limits of the ceramic bodies.]

\section{Propriedades físicas e mecânicas das telhas}

As Figs. 5 a 7 apresentam os valores de absorção de água, retração linear e carga de ruptura à flexão das telhas cerâmicas obtidas a partir das massas MI, MA e MB, respectivamente. É possível observar que a utilização do gnaisse fino possibilitou um pequeno decréscimo na absorção de água e incremento da retração linear das telhas em comparação com a massa industrial MI. Por exemplo, a massa MB, $20 \%$ de finos de gnaisse, apresenta uma redução de 5\% na absorção de água em comparação com massa MI. Entretanto, a absorção de água ainda encontra-se acima do valor máximo permitido por norma que é de $20 \%$ [20]. Este resultado comprova a refratariedade das massas de Campos dos Goytacazes e indica a necessidade da reformulação da massa e alteração em parâmetros de processamento para baixar o nível de porosidade após queima.

Com relação à carga de ruptura, observa-se que,

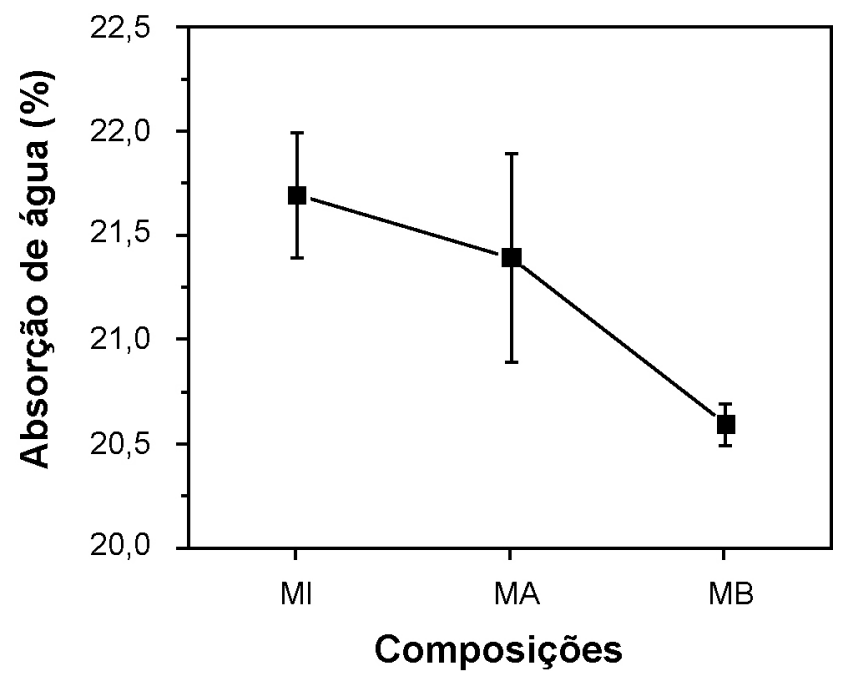

Figura 5: Absorção de água das composições.

[Figure 5: Water absorption of the compositions.]

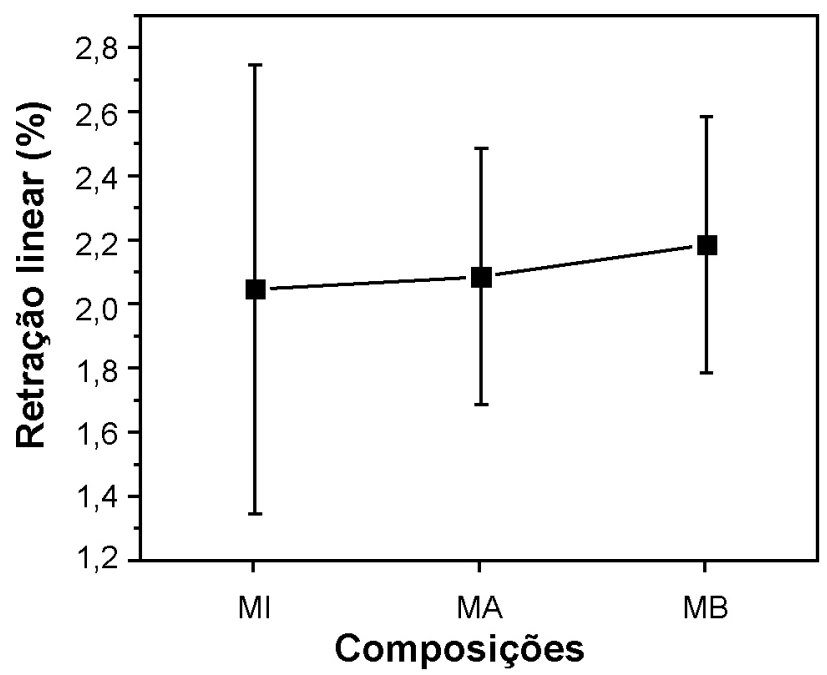

Figura 6: Retração linear das composições. [Figure 6: Linear shrinkage of the compositions.] 


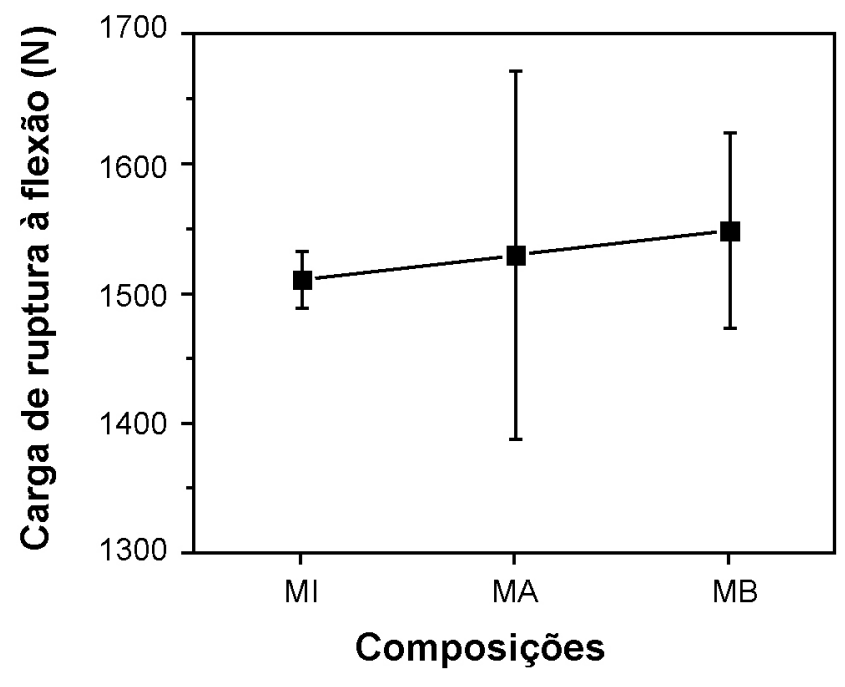

Figura 7: Carga de ruptura à flexão das composições. [Figure 7: Flexural rupture load of the compositions.]

estatisticamente, não há variação com a substituição da areia de quartzo pelo resíduo. Por outro lado, as telhas cerâmicas apresentam valores superiores ao limite mínimo especificado por norma técnica que é de $1300 \mathrm{~N}$ [20]. Estes resultados mostram que os finos de gnaisse não atuaram efetivamente como fundente, e sim mais como material de preenchimento. A tempertatura máxima alcançada, $900{ }^{\circ} \mathrm{C}$, é possivelmente o principal fator limitante para uma maior formação de fase líquida do resíduo.

\section{CONCLUSÕES}

Os finos de gnaisse contribuiram para a redução da plasticidade da massa cerâmica, melhorando sua trabalhabilidade, já que sua plasticidade é relativamente elevada. Isto acarreta redução da quantidade de água necessária para extrudar as peças. Conseqüentemente, a etapa de secagem pode ser realizada de forma mais rápida, com menor gasto energético, e ainda com menores retrações das peças. O Teste Piloto mostrou que nas condições industriais de fabricação de telhas a incorporação de $20 \%$ de finos de gnaisse possibilitou uma redução de 5\% da absorção de água das telhas. Entretanto, isto não foi suficiente para que este parâmetro se enquadrasse dentro da norma. A carga de ruptura à flexão das telhas não foi alterada com a utilização do resíduo. Por outro lado, os valores obtidos foram satisfatórios. Os resultados mostraram ainda que há necessidade de redução da porosidade da cerâmica após queima, mesmo com $20 \%$ de finos de gnaisse incorporado. Isto pode ser obtido com incremento da temperatura e/ou tempo de permanência na temperatura de patamar na etapa de queima das telhas. Pode-se ainda aumentar a reatividade da massa cerâmica por meio do incremento do grau de empacotamento das peças e/ou redução do tamanho de partícula das matériasprimas e ainda reduzir a perda de massa durante a etapa de queima.

\section{AGRADECIMENTOS}

À FAPERJ (Proc. E-26/171.331/2006) e FENORTE/ TECNORTE. Também a colaboração do Sr. João Batista Fernandes Lopes (Patinho), presidente do Sindicato de Extração e Aparelhamento de Gnaisses do Noroeste do Estado do Rio de Janeiro (SINDGNAISSES), na etapa de coleta do resíduo.

\section{REFERÊNCIAS}

[1] A. R. Campos, A. O. Silva, Instalação de Unidades de Tratamento de Efluentes de Serrarias de Rochas Ornamentais, em Santo Antônio de Pádua, RJ, CETEM, Rel. Técnico (1997) p. 23.

[2] S. L. M. de Almeida, A. P. Chaves, L. S. Leal Filho, Primeras Jornadas Iberoamericanas sobre "Caracterización y Normalización de Materiales de Construcción”, Programa CYTED, Madrid, Espanha (2001).

[3] J. M. Caniné, Pedra Miracema, a rocha ornamental de Santo Antônio de Pádua, Departamento de Recursos Minerais, Niterói, RJ (1992).

[4] P. S. Santos, Ciência e Tecnologia das Argilas, 2a Ed., Edgard Blucher, S. Paulo, SP (1989) 4.

[5] A. G. Verduch, Características de las Arcillas Empleadas en la Fabricación de Ladrillos, Técnica Cerâmica 232 (1995) 214-228.

[6] A. R. Lamego, O Homem e o Brejo, 2 ${ }^{\text {a }}$ Ed., Ed. Lidador Ltda., Rio de Janeiro, RJ (1974).

[7] J. R. P. Pinto, Um Pedaço de Terra Chamado Campos, Almeida Artes-gráficas Ed., Campos dos Goytacazes, RJ (1987).

[8] C. M. F. Vieira, J. N. F. Holanda, D. G. Pinatti, Cerâmica 46, 297 (2000) 14-17.

[9] S. N. Monteiro, C. M. F. Vieira, Tile \& Brick Int. 18, 3 (2002) 152-157.

[10] J. N. F. Holanda, C. M. F. Vieira, Mundo Cerâmico IX, 82 (2002) 29-31.

[11] W. D. Kingery, H. K. Bowen, D. R. Uhlmann, Introduction to Ceramics, $2^{\text {nd }}$ Ed., John Wiley \& Sons, New York, EUA (1975) 299.

[12] G. P. Emiliani, F. Corbara, Tecnología Cerámica - Le Materia Prime, Gruppo Editoriale Faenza Editrice, Faenza, Itália (1999) 98.

[13] R. R. Menezes, H. S. Ferreira, G. de A. Neves, H. C. Ferreira, Cerâmica 48, 306 (2002) 92-101.

[14] C. M. F. Vieira, T. M. Soares, R. Sánchez, S. N. Monteiro, Mater. Sci. Engineering A 373, 1-2 (2004) 115121.

[15] A. M. Segadães, M. A. Carvalho, W. Acchar, Appl. Clay Sci. 30, 1 (2005) 42-52.

[16] W. Acchar, F. A. Vieira, D. Hotza, Mater. Sci. Eng. A 419, 1-2 (2006) 306-30.

[17] Associação Brasileira de Normas Técnicas - ABNT, NBR 7181, "Determinação da Análise Granulométrica de Solos", Rio de Janeiro, RJ (1984).

[18] Associação Brasileira de Normas Técnicas - ABNT. 
NBR 6459, "Determinação do limite de plasticidade de solos", Rio de Janeiro, RJ (1984).

[19] Associação Brasileira de Normas Técnicas - ABNT. NBR 7180, "Determinação do limite de liquidez de solos", Rio de Janeiro, RJ (1984).

[20] Associação Brasileira de Normas Técnicas - ABNT. NBR
13310, "Componentes cerâmicos - Telhas - Terminologia, requisitos e métodos de ensaio", Rio de Janeiro, RJ (2005).

[21] M. Marsigli, M. Dondi, Plasticitá delle Argille Italiane per Laterizi e Previsione del Loro Comportamento in Foggiatura, L'Industria dei Laterizi 46, (1997) 214-222.

(Rec. 15/02/2008, Ac. 24/10/2008) 